\title{
LA SEMANTICA DE FREGE
}

Julio C. ARMERO

Dpto. de Lógica y Filosofía de la Ciencia

UNED

Frege es un clásico y, según Borges, clásicos son aquellos autores que leemos con una veneración anticipada. Esta agradable condición de que disfrutan los clásicos no la comparten, ni mucho menos, quienes se ocupan de interpretarlos. Es ley general de la hermenéutica, ciencia por otra parte escasa de principios generales, que cualquier cosa que uno diga sobre un clásico hallará a quien asegure que el clásico nunca tuvo semejante ocurrencia.

Ambos hechos están bien lejos de constituir una paradoja. Por el contrario, son consecuencia de otro principio general de la interpretación, que es el de la caridad. Tendemos a interpretar lo que leemos de forma que logramos un compromiso entre dos factores: atribuir la mayor racionalidad y acierto posibles a lo leído y lograr la mayor simplicidad de nuestras hipótesis analíticas. Pero en el caso del clásico mucha gente está pronta a invertir un gran esfuerzo en la creación de hipótesis analíticas a fin de sostener el acierto del autor.

El intérprete, en cambio, no merece semejantes atenciones, de modo que los hermeneutas no se leen unos a otros con especial caridad: no es raro, pues que entre ellos abunden los malentendidos.

Por otro lado, la corrección de las tesis y argumentos del clásico se aprecia, naturalmente, con respecto a las creencias del intérprete. Esto da un amplio margen a las versiones del clásico.

Éndoxa: Series Filosoficas, $n^{\circ} 2,1993$, UNED, Madrid:

Julio Armero Sanjosé: La semántica de Frege.

pp. 141-151 
Frege es un clásico que presenta, sin embargo, un problema singular: sabemos que su obra cumbre está equivocada. Esto sólo es posible porque las tesis centrales de Frege son extraordinariamente precisas. Por lo tanto la aplicación del principio de caridad no puede dar los mismos resultados que cuando el intérprete se ocupa de clásicos cuyas tesis centrales son más vagas.

La Ley Básica V de los Grundgesetze contiene el error que da origen a la paradoja de Russell. Diversos comentaristas de Frege han tratado de atribuir este error a los aspectos que menos les gustaban del sistema de Frege: a confusiones en el tipo de cuantificación empleada, al uso que hace de la noción de sentido, etc. Creo que, en cambio, desocuparse de estas cuestiones y partir del simple hecho del error ayuda a aclarar algunos aspectos de la lógica de Frege que están bajo enconada discusión. En particular ayuda a poner en claro la famosa cuestión de si Frege tenia o no una semántica y qué papel desempeñaba en su lógica.

Van Heijenoort (11) y Sluga (10) han mantenido que Frege no tenía una semántica o que ésta solo desempeña un papel auxiliar en su obra. Cuando van Heijenoort comenta la obra de Löwenheim dice que en ella "Se tratan varios casos del problema de la decisión y del problema de la reducción mediante el método semántico" y que "Estos resultados y estos métodos eran enteramente ajenos a la corriente Frege-Russell de la lógica" (11, pp. 327-328). Van Heijenoort observa que la cuestión de la completud es en esta corriente, según la terminología de Herbrand, una cuestión experimental. Intentan comprobar si mediante métodos sintácticos son capaces de derivar todas las verdades de la aritmética intuitiva. Podríamos decir que esto es especialmente manifiesto en las cavilaciones de Frege sobre la Ley Básica V después de tener conocimiento de la paradoja de Russell.

Sluga, por su parte, afirma que "Las consideraciones semánticas tienen para él el cometido primario de facilitar la construcción del simbolismo lógico; sólo tienen una función auxiliar" $(10,114$ y véase $\mathrm{p}$. 144). La doctrina de la distinción entre sentido y referencia la introduce Frege para explicar por qué la Ley Básica V se 
debe considerar como una verdad lógica. En "Función y Concepto" Frege pretende mostrar que las extensiones de los conceptos son rangos de valores y que, por lo tanto, la expresión del lado izquierdo de la equivalencia de la Ley Básica $V$ expresa el mismo sentido que la del lado derecho, y, en consecuencia, la verdad de la ley se puede conocer a priori. Este razonamiento semánticoepistemológico tiene consecuencias fatales, pero, de acuerdo con Sluga, Frege no lo considera una prueba, sino una manera de hacer plausible una Ley Básica.

En cambio E. Martin, por ejemplo, piensa que el cometido de la distinción comentada es lograr una prueba de consistencia de las Leyes Básicas. Esta idea se encuadra en otra interpretación de Frege que le atribuye una semántica, e incluso el crédito del origen de la semántica clásica.

Según la pintoresca opinión de Dummett en la semántica clásica el valor de verdad de un enunciado cuantificado está determinado por los valores de verdad de sus instancias, y una instancia es simplemente el resultado de llenar los lugares argumentales con términos singulares (4). Sin embargo, en la semántica de Frege, además de la sustitución tiene un papel fundamental la noción de referencia. Esto es así porque el valor de verdad de los enunciados complejos, construidos por medio de los operadores proposicionales y los cuantificadores, se obtiene a partir del valor de verdad de los atómicos, y la determinación del valor de verdad de éstos apela a los referentes de los términos singulares, puesto que requiere poner términos singulares en los lugares argumentales del enunciado atómico.

Dummett dice que la sustitución es una forma de interpretación: "La noción primitiva de interpretación es la de interpretación por sustitución, esto es, por conversión de una fórmula en una oración auténtica por sustitución de sus letras esquemáticas por expresiones auténticas de los tipos apropiados" (3). Esto en realidad no está muy claro, porque puede estar hablando de dos cosas diferentes: Una, del hecho de que Frege no emplea fórmulas, sino esquemas de fórmulas, y para asignar valores semánticos 
primero hemos de contar con fórmulas, cosa que se consigue efectivamente mediante sustitución, y otra, de que un modelo de un conjunto de fórmulas se puede obtener a partir de un conjunto de cualesquiera cosas, por ejemplo letras o expresiones. Pero parece que Dummett quiere decir por lo menos lo segundo.

Además, siguiendo con las ideas de Dummett, debemos especificar qué propiedades se han de adscribir a las expresiones auténticas que aparecen en las oraciones para poder determinar si son verdaderas o falsas. Esas propiedades son los papeles semánticos de las expresiones. $\mathrm{Y}$ los papeles semánticos consisten en asociar a cada expresión su valor semántico.

Ahora estamos en condiciones, según Dummett, de ver cuál es el papel de la referencia en la semántica de Frege: lo que éste identifica cono referente de una expresión es lo que se ha de considerar su papel semántico $(3,150)$. Las reglas de la sintaxis intentan garantizar, en la interpretación que Dummett hace de Frege, que toda expresión bien formada tiene referencia si lo tienen sus partes constituyentes. Frege, de hecho, dedica cinco párrafos de los Grundgesetze a intentar demostrar que todo nombre bien formado de su lenguaje formal tiene referencia. Esta debería ser una demostración inductiva cuidadosa, porque dada una noción sustitucional de la referencia cualquier clase sintáctica puede ser considerada como referencial (Quine,9). Pero Frege no es cuidadoso. En realidad esa parte de los Grundgesetze tiene que contener un error, porque si todas las expresiones del lenguaje formal de Frege tuvieran referencia entonces no se produciría la paradoja de Russell.

En la terminología de Frege la referencia de las oraciones es lo verdadero o lo falso. E. Martin sostiene que lo que Frege espera mostrar es que todas las oraciones de los Grundgesetze tienen un valor de verdad. Puesto que cada Ley Básica debería ser verdadera y las reglas de inferencia aseguran que a partir de premisas verdaderas sólo se alcanzan conclusiones verdaderas, el sistema debería ser consistente. Esto es otra manera de señalar, dado que el sistema no es consistente, que algo ha debido ir mal en la 
prueba de que toda expresión tiene referencia, y en particular que las oraciones refieren a lo verdadero o a lo falso.

Lo primero que ha ido mal es que la demostración tiene pinta de ser inductiva, pero no lo es: falta la base de inducción. E. Martin (7) piensa que los problemas resultantes proceden de que Frege usa dos nociones de referencia: una de acuerdo con sus criterios y otra objetual, y sus criterios son sustitucionales, si son algo.

Tanto Dummett como E. Martin atribuyen a Frege una semántica categorial, pero J. N. Martin (8) cree que es precisamente esa interpretación de Frege la que hace que su semántica tenga lagunas y sugiere que atribuyendo a Frege otra semántica se evitarían muchas de esas indefiniciones.

Esta variedad de opiniones encontradas quizá pueda ser sustanciada si echamos un vistazo a las explicaciones que da Frege sobre las expresiones de su lenguaje conceptual. Algunas de estas explicaciones se pueden entender como las reglas de formación de su sistema. La distinción básica es la que hay entre nombres propios y nombres de funciones. Esta distinción la establece Frege sintácticamente, y luego procede a clasificar los nombres de las funciones por el número de sus lugares argumentales y por la naturaleza de los argumentos, lo que determina el nivel de la función.

Parece que Frege piensa que esa clasificación da lugar a una jerarquía de nombres, en cuyo nivel más bajo encontramos los nombres propios sin lugares argumentales. Algunos intérpretes de Frege hablan como si los nombres propios nunca tuvieran lugares argumentales, pero Frege dice expresamente que a algunos nombres propios se les puede quitar una parte que sea también un nombre propio.

En el nivel 1, con el tipo 1, están los nombres de funciones de un lugar argumental que se puede llenar con nombres propios. $\mathrm{Si}$ ese lugar es llenado por un nombre propio lo que obtenemos es otro nombre propio. 
En el mismo nivel, pero con dos lugares argumentales están los nombres de funciones de tipo 2.

En el nivel siguiente, en cambio, están los nombres de funciones con lugares argumentales para un nombre de una función de primer nivel, y también con varios lugares para varios nombres de funciones de primer nivel.

Aunque Frege dice que estas aclaraciones bastan para hacerse una idea de qué tipos de nombres hay, quizá encomendando al lector la tarea de formar otros nombres de funciones, varios parágrafos más atrás encontramos nombres de funciones que tienen lugares argumentales de niveles diferentes, por ejemplo para un nombre de función de primer nivel y un nombre de objeto.

Las funciones primitivas que emplea Frege son la horizontal, la negación, la diagonal o descriptor, el condicional, la identidad, el generalizador de primer orden, el curso de valores y la cuantificación de orden superior para funciones de uno y dos lugares argumentales.

De acuerdo con las definiciones de Frege, cuando se llena el lugar argumental que ha de ser llenado con un nombre de función en un nombre de función de segundo nivel debemos tener un nombre de función de primer nivel. Sin embargo, cuando hacemos esto en un nombre de un curso de valores lo que obtenemos son directamente objetos. Esto es lo que hace que, a pesar de la aparente estratificación de su lenguaje, no se pueda formar en él una teoría de tipos, que evitaría la paradoja.

Frege mismo, por otro lado, se da cuenta de que su manera de introducir los cursos de valores no le permite conocer qué valores toma una función cuando sus argumentos son cursos de valores. El pasaje donde Frege reconoce esto contiene, por cierto, una argumentación al efecto de que no es necesario introducir en la sintaxis de su lenguaje conceptual nombres para los valores de verdad, porque cada uno de estos objetos se puede identificar por estipulación con un curso de valores. 
Frege da además unas explicaciones para reconocer cuándo un nombre denota algo. De ellas dice que no se deben considerar definiciones de "tiene denotación" o "tiene referencia", porque se basan en la suposición de que algunos nombres denotan. Añade que, por consiguiente, sirven para ampliar el conjunto de nombres con denotación. Sin embargo, puesto que en otro lugar Frege intenta demostrar que todos los nombres primitivos de su sistema refieren, parece que en conjunto cree que tiene una definición inductiva de cuándo un nombre refiere. El pasaje aludido parece ser el que presta apoyo a Dummett para decir (4) que en el enfoque de Frege, en vez de construir una teoría semántica para el lenguaje (de la aritmética, por ejemplo) la construimos para una expansión de ese lenguaje.

En la semántica ordinaria una oración cuantificada universalmente es verdadera si la oración abierta resultante de sustituir las variables ligadas por variables libres es satisfecha por todos los objetos (o secuencias de objetos) del dominio de interpretación. Dummett dice que esto es una simple variación del enfoque de Frege. Pero en realidad es muy semejante a una de las ideas de Frege y profundamente distinto de otra de las ideas de Frege. $Y$ es esta idea la que además aparece en las reglas sobre la denotación.

Las reglas semánticas de Frege son cinco:

1) Un nombre de una función de primer nivel con un argumento refiere o denota si siempre que llenamos los lugar argumentales de la función con nombres propios que denotan obtenemos un nombre propio que denota.

2) Un nombre propio denota si denota el nombre propio que resulta de llenar con ese nombre nombre propio los lugares argumentales del nombre de una función de primer nivel que denota de un solo argumento. También denota un nombre propio si tiene denotación el nombre de la función de primer nivel de un solo argumento que resulta de llenar, en un nombre de función de primer nivel con dos argumentos, los lugares correspondientes a un argumento con ese nombre propio. 
3) Un nombre de función de primer nivel con dos argumentos denota si tiene denotación el nombre propio que resulta de llenar cada uno de sus lugares argumentales con nombres propios que denoten.

4) Un nombre de función de segundo nivel de un argumento para funciones de primer nivel de un argumento denota si, siempre que denote el nombre de la función de primer nivel, denota el nombre propio que obtenemos al llenar con este nombre de función los lugares argumentales de la función de segundo nivel.

Puesto que Frege no usa más que una proposición en que aparezcan funciones de tercer nivel, no se toma la molestia de explicar la construcción y las condiciones de denotación de este tipo de funciones salvo para un caso particular. Esta función tiene un solo argumento para funciones de segundo nivel con un solo argumento que a su vez ocupan funciones de primer nivel de un solo argumento. Este nombre de función de tercer nivel denota si, siempre que denota un nombre de función de segundo nivel como la indicada, denota el nombre propio que resulta de ponerla en el lugar argumental de la función de tercer nivel.

Los nombres primitivos que aparecen en el sistema de Frege son todos nombres de funciones, así que falta la base para que estas reglas puedan constituir una definición inductiva de "tener denotación". Pero aun contando con esto surgen algunas dudas: el generalizador es una función de segundo nivel y, de acuerdo con la regla 4, una fórmula cuantificada universalmente denota cuando por sustitución obtenemos nombres que denotan. Sin embargo, en el párrafo 8 de los Grundgesetze, Frege olvida por un momento hablar de nombres que tienen lugares argumentales, y dice que una fórmula con cuantificador universal es verdadera si la fórmula abierta correspondiente es verdadera para todo argumento. Aunque esto es un descuido, Frege saca partido ocasionalmente de la interpretación referencial de la cuantificación.

Como muchas veces se ha señalado, esa confusión puede hacernos pensar que Frege creía que cada objeto tiene un nombre. 
Pero aparte de otras razones para pensar lo contrario, una de las cosas que Frege debía tener más presentes es el teorema de Cantor.

Estas dos formas de entender la cuantificación no son, desde luego, variaciones de una misma idea, como asegura Dummett. Veamos cuán diferentes son.

Quine (9) ha observado acertadamente que en la cuantificación sustitucional pueden explicarse cuantificadores adicionales cuyas variables ocupen el lugar de las palabras de cualquier categoría sintáctica. Es decir, si en una oración cualquiera tomamos una expresión y determinamos la clase de las expresiones que la pueden reemplazar manteniendo la buena forma de la oración, podemos inventar una variable que tenga por rango esa clase de expresiones y cuantificar sobre ella cuando queramos. Desde luego a nadie se le ocurriría postular un dominio de objetos llamados respectivamente "hacia", "para", "por", etc. Este tipo de cuantificación no suministra medios para distinguir los nombres (propios, en la terminología de Frege) de otras categorías sintácticas.

En las informales reglas sintácticas de Frege aparecen los nombres propios, aunque no se sabe lo que son: todos los términos primitivos son funciones. Pero eso no quiere decir que Frege considere irrelevante esa categoría sintáctica. Al contrario, todas sus explicaciones de los demás términos se basan en la categoría de nombre propio.

En la teoría aritmética, que Frege trata de expresar en términos lógicos, hay, sin duda, nombres propios para números. Pero el hecho de que Frege no se proponga crear un lenguaje que contenga todos los nombres, sino ofrecer recursos para poder nombrar cualquier objeto que se tercie, hace pensar que Frege era consciente de la imposibilidad de nombrar a todos los números. Quine señala que es posible especificar cualquier número real que no tenga nombre en la teoría aritmética que formalizamos, ya que podemos expandir la teoría de manera que posea nombres para más números reales. Pero especificar un número real que no esté nombrado en la teoría requiere, como ahora se sabe, una teoría de fondo más potente que la teoría objeto. Frege, en cambio, no lo 
sabía, y esta circunstancia está conectada con la siguiente observación de Quine.

La cuestión de la ontología, o de la referencialidad, es internamente indiferente para cualquier teoría completa y decidible. La cuestión del dominio de las variables solo importa desde la perspectiva de una teoría de fondo más potente que no sea decidible a su vez.

Frege no se planteaba cuestiones metateóricas, pero creía que su sistema era completo y consistente, y no parece que se planteara el problema de la decisión, así que pensaba que los recursos de la cuantificación sustitucional son equivalentes a los de la cuantificación referencial. Es cierto que él insistía en la importancia del significado y la referencia de los términos de su sistema, y criticaba acerbamente la falta de interés por estos aspectos que parece evidente en el enfoque formalista de Hilbert.

Sin embargo, y esto es curioso, Frege critica también el que probablemente era el único método semántico genuino de la época, y quien lo practicaba era Hilbert. Las pruebas de independencia y de consistencia que hace Hilbert de los axiomas de la geometría son semánticas. Se basan en traducir los términos de los axiomas a otro lenguaje y ver qué ocurre con los valores de verdad resultantes. A Frege este procedimiento no le gustaba gran cosa, aunque en "Sobre los Fundamentos de la Geometría" concedió que no había nada que objetar si admitimos solamente la traducción dentro de un mismo lenguaje. Pero es, claramente, otro error de Frege, porque todo lo que se ha hecho en semántica demuestra que es necesaria una teoría de fondo.

Así que, para finalizar, ¿cuál es la situación de Frege respecto a la semántica? Dice bastantes cosas sobre semántica, y parece creer que necesita las tesis y definiciones que ofrece. Pero cree que para su teoría hay una interpretación única, que no necesita una teoría de fondo, que su teoría es consistente y completa. Esto es tanto como creer que no necesita la semántica, si interpretamos "creer" como de re. De hecho no hace el menor uso de métodos semánticos, su sistema prácticamente prohíbe su uso y critica a 
quienes los emplean. Si alguien pretende decir que Frege tiene una semántica, lo más que se le puede conceder es que, a partir de su discusión de ciertos términos semánticos y de algunas indicaciones ocasionales suyas, un lógico posterior podría orientar la construcción de una semántica, y la podría llamar "fregeana" por cortesía histórica.

\section{BIBLIOGRAFIA}

(1)CURRIE G. Frege. An Introduction to His Philosophy, Brighton, 1982.

(2)DUMMETT M. Frege. Philosophy of Language, $2^{\mathrm{a}}$ ed.,Londres, 1981.

(3)DUMMETT M. The Interpretation of Frege's Philosophy, Londres, 1981.

(4)DUMMETT M,"Realism", Synthese, 52, 1982.

(5)FREGE G. Grundgesetze der Arithmetik, Jena, 1893. Traducción parcial al inglés de M. Furth, Berkeley, 1964.

(6)FREGE G. "Über die Grundlagen del Geometrie", J.D.M.V., xv, 1906. Traducción al inglés de M.E. Szabo, The Philosophical Review, 69, 1960.

(7) MARTIN E.(Jr). "Referentiality in Frege's 'Grundgesetze'", History and Philosophy of Logic, 3, 1982.

(8) MARTIN J.N. "The Semantics of Frege's 'Grundgesetze'", History and Philosophy of Logic, 5, 1984.

(9) QUINE W. Ontological Relatioiy and Other Essays, Nueva York, 1969

(10) SLUGA H. Gottlob Frege, Londres, 1980.

(11) HEIJENOORT J.van "Logic as Calculus and Logic as Language", Synthese, 17, 1967. 